\title{
Perancangan Ulang Website Teknik Industri Universitas Islam Negeri Sultan Syarif Kasim Riau dengan Memperhatikan Aspek Usabilitas Menggunakan Metode Waterfall
}

\author{
Melfa Yola ${ }^{1}$, Angga Gustiandi ${ }^{2}$ \\ ${ }^{1,2}$ Jurusan TeknikIndustri, Fakultas Sains dan Teknologi Universitas Islam Negeri Sultan Syarif Kasim Riau \\ Jl. HR. Soebrantas KM. 18No.155 Simpang Baru, Panam, Pekanbaru, 28293 \\ Email: melfa.yola.uin-suska.ac.id, angga.gustiandi@gmail.com
}

\begin{abstract}
ABSTRAK
Dalam era teknologi saat ini, informasi harus bisa dengan cepat didapatkan dengan cara yang efisien. Jika pencarian informasi yang dibutuhkan, seperti informasi akademik maupun non akademik pada suatu Jurusan di sebuah Perguruan Tinggi dilakukan dengan cara klasik melalui kertas, maka cara ini tidak akan cukup efisien. Seiring dengan kemajuan teknologi informasi dan untuk menjamin tercapainya mutu Perguruan Tinggi yang baik, saat ini sistem informasi berbasis website merupakan sarana yang mendasar dan dapat memenuhi kebutuhan pengguna bagi suatu Prodi di sebuah Perguruan Tinggi. Website Program Studi Teknik Industri dirancang dengan fitur-fitur yang bervariasi dan memperhatikan tingkat usabilitas pada website tersebut. Pada hasil rancangan website, diusulkan SOP pemeliharaan agar website yang dihasilkan dapat diakses secara berkelanjutan dan dapat memberikan informasi-informasi yang dibutuhkan. Website dirancang menggunakan model waterfall, yang mana model ini digunakan untuk merancang sebuah sistem secara bertahap. Proses pengumpulan data dilakukan dengan Focus Group Discussion (FGD) untuk mendapatkan kebutuhan-kebutuhan pengguna dan dari kebutuhan tersebut akan diimplementasikan kedalam website. Pengujian tingkat usabilitas website menggunakan kuesioner WEBUSE mendapatkan level usabilitas dengan rincian kategori Content, Organization, and Readability bernilai 0.7488 , Navigation and Link bernilai 0.7476 , Desain User Interface bernilai 0.7512 dan Performance and Effectiveness bernilai 0.7381. Berdasarkan level usabilitas yang didapatkan, website yang dihasilkan dapat memudahkan pengguna dalam mendapatkan suatu informasi yang diinginkan.
\end{abstract}

Kata Kunci : Website, Waterfall, FGD, WEBUSE, UML

\section{Pendahuluan}

Website merupakan alamat atau lokasi di dalam internet suatu halaman web, umumnya membuat dokumen HTML dan dapat berisi sejumlah foto atau gambar grafis, musik, teks bahkan gambar yang bergerak. Dengan menggunakan website, informasi dapat diakses selama 24 jam dalam satu hari dan dikelola oleh mesin sehingga pengguna dapat mendapatkan informasi berupa gambar-gambar, suara, file video dan lain-lain yang disediakan dalam sebuah web server (Yumarlin, 2016) [11].

Website dirancang untuk dapat membantu pengguna dalam mencapai tujuannya. Oleh karena itu, website sebaiknya memiliki kemudahan dalam pemakaiannya (usabilitas). Usabilitas didefinisikan sebagai sejauh mana produk dapat digunakan oleh pengguna spesifik dengan tujuan efektifitas, efisiensi dan kepuasan dalam pengguna konteks yang spesifik (Rubin dan Chisnell, 2008) [9]. Website harus dirancang lebih efektif dengan prinsip human-centred design, sehingga memudahkan pengguna dalam menggunakan website tersebut. Website harus dirancang dengan memperhatikan semua kekurangan dan kelebihan agar dapat menghasilkan website yang bersifat usable (Yumarlin, 2016) [11].

Dengan adanya website pada setiap prodi, akan membantu mahasiswa, alumni, dosen, dan pihak eksternal dalam mencari suatu informasi tentang Program Studi Teknik Industri Universitas Islam Negeri Sultan Syarif Kasim Riau. Apabila jurusan mempunyai website, hal ini akan memudahkan suatu Universitas untuk meraih status sebagai World Class University (WCU), dikarenakan setiap prodi dapat memperkenalkan 
dirinya kepada dunia sehingga akan ada ketertarikan masyarakat luar negeri yang ingin berkuliah pada jurusan tersebut sehingga status sebagai WCU dapat terealisasi.

Teknik industri Universitas Islam Negeri Sultan Syarif Kasim Riau sebelumnya telah mempunyai website sendiri dengan beralamatkan http://ie.uin-suska.ac.id, dan postingan terakhir website tersebut ialah pada tahun 2015. Website Teknik Industri Universitas Islam Negeri Sultan Syarif Kasim Riau yang lama ini sudah tidak dapat digunakan lagi dikarenakan tidak adanya tim pengelola website yang bertugas dalam pengoperasian website, sehingga website tersebut tidak memberikan informasi dan tidak bisa di akses lagi.

Dalam melakukan perancangan sebuah website harus dilakukan secara bertahap sehingga website yang dihasilkan dapat lebih tertata dengan baik. Prosedur pengembangan yang biasa digunakan pada sistem informasi yaitu model waterfall. Model ini melakukan pendekatan secara sistematis dan urut mulai dari level kebutuhan sistem lalu menuju ke tahap analisa, desain, coding, testing dan maintenance. Model ini disebut dengan waterfall karena tahap demi tahap yang dilalui harus menunggu selesainya tahap sebelumnya dan berjalan berurutan (Royce, 1970 dalam Bassil, 2012) [1].

\section{Tinjauan Pustaka}

\section{Sistem Informasi}

Perkembangan teknologi di era modern saat ini mengalami kemajuan yang sangat pesat, dimana setiap orang dapat menemui berbagi teknologi di berbagai bidang di sekitar kehidupan manusia yaitu salah satunya adalah dengan adanya teknologi informasi. Teknologi informasi merupakan suatu alat yang dapat memberikan suatu informasi kepada penggunanya untuk memperoleh data atau informasi yang dapat mendukung ketepatan dalam mengambil keputusan dengan menggunakan teknologi yang tepat guna (Lasminiasih dkk, 2016) [5].

\section{Waterfall}

Dalam melakukan perancangan sebuah website harus dilakukan secara bertahap sehingga website yang dihasilkan dapat lebih tertata dengan baik. Prosedur pengembangan yang biasa digunakan pada sistem informasi yaitu model waterfall. Model ini melakukan pendekatan secara sistematis dan urut mulai dari level kebutuhan sistem lalu menuju ke tahap analisa, desain, coding, testing dan maintenance. Model ini disebut dengan waterfall karena tahap demi tahap yang dilalui harus menunggu selesainya tahap sebelumnya dan berjalan berurutan (Royce, 1970 dalam Bassil, 2012).

Secara umum tahapan pada model waterfall dapat dilihat pada gambar 2 berikut.

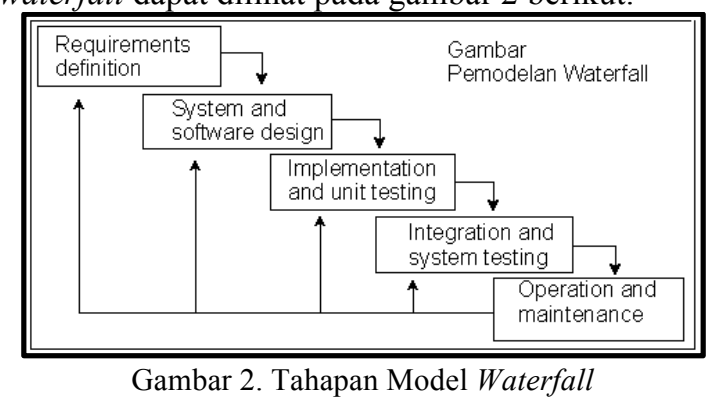

\section{Focus Group Discussion}

FGD merupakan jenis metodologi penelitian kualitatif atau dapat didefinisikan sebagai suatu diskusi terstruktur dengan sekelompok kecil orang yang dijalankan oleh seorang fasilitator atau menggunakan tim moderator untuk menghasilkan data kualitatif tentang suatu topik dan menggunakan serangkaian pertanyaan terbuka (Masadeh, 2012) [7].

Pelaksanaan Focus Group Discussion dibagi menjadi 8 tahap (Bergells, 2008 dalam Wirandoko, 2009) [10]. Langkah-langkahnya terdiri dari:

1. Menentukan tujuan diskusi

Tujuan diskusi harus ditentukan sebelum diskusi dimulai sehingga jalannya diskusi tidak keluar dari topik yang dibicarakan.

2. Menyatakan hipotesis awal

Tahap ini menyatakan problem atau masalah yang sedang dihadapi. Hal ini dapat membantu memperkuat tujuan diskusi dan menentukan arah diskusi.

3. Menentukan populasi

Tahap ini untuk mengetahui sia saja yang terlibat atau berhubungan dengan suatu masalah yang didiskusikan

4. Pemilihan peserta

Pemilihan peserta harus sesuai dengan objek yang dipelajari dengan orang-orang yang kompeten.

5. Membuat panduan diskusi

Panduan ini digunakan oleh moderator untuk memandu jalannya diskusi. Hal ini berguna untuk menjaga agar diskusi tetap sesuai topik 
yang dibahas dan dapat mengendalikan jalannya diskusi.

6. Uji coba

Ujicoba dilakukan agar diskusi dapat berjalan lancar nantinya. Dilakukan sebagai pemanasan sebelum melakukan diskusi dan mengetahui aturan yang disepakati.

7. Melakukan FGD

FGD dipimpin oleh seorang moderator. Moderator menjaga agar jalannya diskusi tetap kondusif dan terfokus. Semjua pendapat peserta dicatat.

8. Analisis hasil

Hasil dari FGD dilakukan tahap analisis untuk dapat diaplikasikan untuk penyelesaian masalah.

4. UML

Menurut Windu Gata, Grace (2013:4), Unified Modeling Language (UML) adalah bahasa spesifikasi standar yang dipergunakan untuk mendokumentasikan, menspesifikasikan dan membanngun perangkat lunak. UML merupakan metodologi dalam mengembangkan sistem berorientasi objek dan juga merupakan alat untuk mendukung pengembangan sistem.

Alat bantu yang digunakan dalam perancangan berorientasi objek berbasiskan UML adalah sebagai berikut (Hendini, 2016) [3] :

1. Usecase Diagram

Usecase diagram merupakan pemodelan untuk kelakuakn (behavior) sistem informasi yang akan dibuat. Use case digunakan untuk mengetahui fungsi apa saja yang ada di dalam sistem informasi dan siapa saja yang berhak menggunakan fungsi-fungsi tersebut.

2. Activity Diagram

Diagram aktivitas menggambarkan workflow (aliran kerja) atau aktivitas dari sebuah sistem atau proses bisnis.

3. Sequence Diagram

Diagram urutan mengagmbarkan kelakuan objek pada use case dengan mendeskripsikan waktu hidup objek dan pesam yang dikirim dan diterima antar objek.

\section{Usabilitas}

Usability pada umumnya diukur dengan melibatkan sejumlah pengguna yang dipilih sebagai perwakilan dari pengguna sebelumnya. Pengguna tersebut akan menggunakan sistem untuk menyelenggarakan serangkaian tugas khusus, meskipun sistem tersebut juga dapat diukur dengan melibatkan pengguna sesungguhnya di lapangan untuk melakukan tugas apapun yang memang sedang dilakukan (Schumacher dan Lowry, 2010 dalam Ichsani, 2017) [4].

Adanya 5 syarat yang harus dipenuhi agar suatu website mencapai tingkat usability yang ideal, yaitu: Learnability (Mudah dipelajari), Efficiency (Efisien), Memorability (Kemudahan dalam mengingat), Errors (Pencegahan kesalahan), dan Satisfaction (Kepuasan pengguna). Teknologi adalah suatu rancangan langkah instrumental untuk memperkecil keraguan mengenai hubungan sebab akibat dalam mencapai hasil yang diharapkan (Nielsen, 2003) [6].

\section{WEBUSE}

WEBUSE (Website Usability Evaluation Tool) merupakan suatu kuesioner yang dikembangkan dari 4 buah usability evaluation tool, yaitu WAMMI, WebSAT, Bobby, dan protocol analysis. untuk mengevaluasi usabilitas web. Kuesioner ini terdiri dari 24 pertanyaan dengan 5 opsi jawaban yang terbagi dalam 4 kategori, yaitu Content, Organization, and Readability, Navigation and Links, Desain User Interface, Performance and Effectiveness. WEBUSE dapat digunakan untuk semua jenis website, selain itu pembuat WEBUSE mengklaim bahwa evaluasi menggunakan WEBUSE adalah reliable dan telah mendapat tanggapan yang memuaskan dari user. (Chiew dan Salim, 2003) [2]. Tabel 1 Opsi Jawaban Kuesioner WEBUSE

\begin{tabular}{|c|c|c|c|c|c|}
\hline Opsi & $\begin{array}{c}\text { Sangat } \\
\text { Setuju }\end{array}$ & Setuju & Standar & $\begin{array}{c}\text { Tidak } \\
\text { Setuju }\end{array}$ & $\begin{array}{c}\text { Sangat Tidak } \\
\text { Setuju }\end{array}$ \\
\hline Nilai & 1,00 & 0,75 & 0,5 & 0,25 & 0,00 \\
\hline
\end{tabular}

Sumber : Chiew dan Salim (2003) [2]

Dari kuesioner WEBUSE, dapat diperoleh nilai yang dapat menggambarkan seberapa baik level usabilitas pada suatu website. Nilai tersebut terbagi dalam 5 range nilai dimana setiap range nilai mewakili tingkatan baik buruknya usabilitas.

Tabel 2 Usability point and corresponding usability tool

\begin{tabular}{|c|c|c|c|c|c|}
\hline Poin & $0 \leq \mathrm{x} \leq$ & $0,2 \leq \mathrm{x} \leq$ & $0,4 \leq \mathrm{x} \leq$ & $0,6 \leq \mathrm{x} \leq$ & $0,8 \leq \mathrm{x} \leq$ \\
ts, $\mathrm{x}$ & 0,2 & 0,4 & 0,6 & 0,8 & 1,0 \\
\hline Nilai & Bad & Poor & $\begin{array}{c}\text { Moderat } \\
\mathrm{e}\end{array}$ & Good & Excellent \\
& & & & & \\
\hline
\end{tabular}

Sumber : Chiew dan Salim (2003) [2]

Kemudian merit diakumulasikan

berdasarkan 5 kategori usability. Mean value untuk setiap kategori dianggap sebagai poin usability 
untuk setiap kategori. Poin usability untuk kategori $\mathrm{x}$ didefinisikan dalam rumus 1 .

$\mathrm{X}=\frac{\left.\left[\sum \text { (nilai untuk setiap pertanyaan pada kategori }\right)\right]}{[\text { jumlah pertanyaan }]}$

Sedangkan 24 pertanyaan yang tersusun dalam kuesioner WEBUSE adalah sebagai berikut :

1. Pertanyaan untuk mengevaluasi content, organisation dan readability yaitu :

a. Website mengandung materi dan topik menarik dan selalu ter-update.

b. Saya merasa mudah menemukan apa yang saya inginkan di dalam website.

c. Isi yang terdapat dalam website tersusun atau terorganisasi dengan baik.

d. Saya merasa mudah membaca isi atau content website.

e. Saya merasa nyaman dan terbiasa dengan bahasa yang digunakan

f. Saya tidak perlu menggunakan scroll ke kiri dan ke kanan ketika membaca content website.

2. Pertanyaan untuk mengevaluasi navigation dan links yaitu :

a. Saya merasa mudah mengetahui posisi keberadaan ketika menjelajah website.

b. Website mempunyai petunjuk dan link yang mempermudah saya memperoleh informasi yang diinginkan.

c. Saya merasa mudah menjelajah website menggunakan link yang ada atau tombol back pada browser.

d. Link dalam website terpelihara dengan baik dan ter-update.

e. Website tidak terlalu banyak membuka browser windows baru ketika saya menjelajahi website.

f. Penempatan links atau menu disusun secara standar dan mudah dikenali.

3. Pertanyaan untuk mengevaluasi user interface design yaitu :

a. Desain interface website atraktif.

b. Saya merasa nyaman dengan warna yang digunakan dalam website.

c. Website tidak mengandung fitur yang mengganggu seperti scrolling atau blinking teks dan animasi berulang.

d. Website mempunyai tampilan yang konsisten.

e. Website tidak terlalu banyak mengandung web advertisment. f. Desain website menimbulkan ketertarikan dan mudah dipelajari cara penggunaanya.

4. Pertanyaan untuk mengevaluasi performance and effectiveness yaitu :

a. Saya tidak perlu menunggu terlalu lama untuk download file atau membuka suatu halaman.

b. Saya merasa mudah membedakan links yang sudah dan belum dikunjungi.

c. Saya bisa dengan mudah mengakses website ini di sepanjang waktu.

d. Website memberi respon yang sesuai dengan harapan untuk semua aksi yang dilakukan.

e. Saya merasa efisien ketika menggunaka website.

f. Website selalu memberikan pesan yang jelas dan berguna ketika saya merasa tidak tahu bagaimana untuk memproses suatu hal.

\section{SOP (Standard Operating Procedure)}

SOP merupakan serangkaian panduan yang terdokumentasi secara jelas, lengkap, dan rinci mengenai proses, tugas, dan peran setiap individu atau kelompok yang dilakukan sehari-hari di dalam suatu organisasi. Dilihat dari fungsinya, SOP berfungsi membentuk sistem kerja dan aliran kerja yang teratur, sistematis, serta dapat dipertanggung jawabkan dan menggambarkan tujuan pekerjaan yang dilaksanakan sesuai dengan kebijakan dan peraturan yang berlaku (Rachmi dkk, 2014) [8].

\section{Metode Penelitian}

Penelitian ini bertujuan untuk memperbaiki desain website Teknik Industri UIN SUSKA Riau dengan memperhatikan aspek usabilitas.

1. Requirements Analysis and Definition Tahapan pertama dalam metode waterfall ialah tahapan Requirements Analysis and Definition yang mana pada tahap ini peneliti mencari kebutuhan informasi yang akan diimplementasikan kedalam website. Pada tahapan ini proses pengambilan data menggunakan metode Focus Group Discussion (FGD). FGD dilakukan sebanyak 5 kali dengan beberapa pihak diantaranya adalah pihak mahasiswa, asisten dosen, alumni, dosen dan pihak eksternal dengan durasi $30-50$ menit setiap FGD yang dilakukan 
2. System and Software Design

Pada tahapan ini di rancang 3 diagram yang menggambarkan website sebelum di implementasikan. Diagram yang akan dirancang adalah Usecase Diagram, Activity Diagram, dan Sequence Diagram.

3. Implementation and Unit Testing Pada tahapan ini dilakukan implementasi dari hasil FGD yang telah dilakukan.

4. Integration and System Testing Pengujian ini menggunakan kuesioner WEBUSE dan disebarkan kepada 35 responden yang terdiri dari mahasiswa, alumni, pihak eksternal dan pihak jurusan Teknik Industri Universitas Islam Negeri Sultan Syarif Kasim Riau.

5. Operation and Maintenance

Pada tahap ini dilakukan perancangan usulan SOP pemeliharaan website Teknik Industri, agar website ini dapat berfungsi dengan baik lagi serta memberikan informasi yang update bagi mahasiwa, alumni, dosen serta pengguna yang berada di luar prodi Teknik Industri.

6. Analisis dan Interpretasi Hasil

Berdasarkan pengolahan data yang telah dilakukan dan pengujian usabilitas desain usulan, maka langkah selanjutnya adalah melakukan analisis dan interpretasi hasil. Pada tahap ini dilakukan analisis terhadap hasil rancangan desain website teknik Industri Universitas Islam Negeri Sultan Syarif Kasim Riau. Analisa yang dilakukan meliputi analisa desain hasil rancangan dan juga evaluasi pada tingkat usabilitas yang didapatkan.

\section{Hasil dan Pembahasan}

\section{Focus Group Discussion}

Focus Group Discussion dilakukan beberapa kali agar tujuan dari dilaksanakannya FGD dapat tercapai, yaitu untuk mencari detail permaalahan yang terjadi, memperoleh masukan, dan juga prioritas untuk perbaikan desain website Teknik Industri Universitas Islam Negeri Sultan Syarif Kasim Riau terkait uabilitas. Pada penelitian kali ini dilakukan FGD sebanyak 5 kali yang melibatkan FGD terhadap Mahassiswa, FGD terhadap Asdos, FGD terhadap HMJ, FGD terhadap Alumni dan FGD Terhadap Dosen.

\section{Identifikasi dan Pengelompokkan Masalah}

Berdasarkan Focus Group Discussion yang dilakukan, beberapa masukan dari anggota FGD juga berhasil diidentifikasi. Beberapa masukan bertujuan untuk lebih meningkatkan kepuasan pengguna, sehingga dapat menghasilkan website dengan tingkat usabilitas yang tinggi. Beberapa masukan yang diperoleh adalah sebagai berikut :

1. Penambahan menu-menu untuk memudahkan para pengguna dalam memperoleh informasi

2. Penambahan info-info terkait jurusan Teknik Industri

3. Gambar harus mencerminkan jurusan Teknik Industri

4. Penambahan tombol search

5. Tampilan background pada setiap page harus lebih menarik

6. Penambahan widget yang tersambung ke beberapa link

7. Link tersambung ke beberapa situs

8. Perpaduan warna pada website harus melambangkan Teknik Industri Universitas Islam Negeri Sultan Syarif Kasim Riau

9. Form-form yang dapat di download

10. Berita-berita tentang jurusan Teknik Industri harus update.

11. Terdapat galeri yang berhubungan dengan kegiatan jurusan Teknik Industri

12. Penggunaan bahasa harus konsisten

13 Sertifikat akreditas jurusan Teknik Industri yang dapat di download

\section{Prioritas Penyelesaian yang Akan Dilakukan}

Semua masukkan dan pengelompokkan masalah akan diimplementasikan kedalam website sehingga dapat menghasilkan website yang memiliki tingkat usabilitas yang tinggi. Ada 13 kelompok masukan yang akan diimplementasikan kedalam website Teknik Industri Universitas Islam Negeri Sultan Syarif Kasim Riau.

\section{Desain Sistem}

Pada tahapan ini, akan dilakukan desain sistem yang digunakan untuk mengalokasikan kebutuhan-kebutuhan sistem baik perangkat keras maupun perangkat lunak dengan membentuk arsitektur sistem secara keseluruhan. Pada langkah ini akan dilakukan pembuatan rancangan diagram yang menggambarkan hubungan antara user dengan sistem. Ada tiga diagram yang akan dibuat dalam penelitian ini, diagram tersebut adalah Usecase Diagram, Activity Diagram, dan Sequence Diagram.

\subsection{Usecase Diagram}


Usecase diagram merupakan fungsional yang disediakan sistem sebagai unit-unit yang saling bertukar pesan antar unit. Adapun Usecase diagram pada penelitian ini dapat dilihat pada gambar 4.1 di bawah ini.

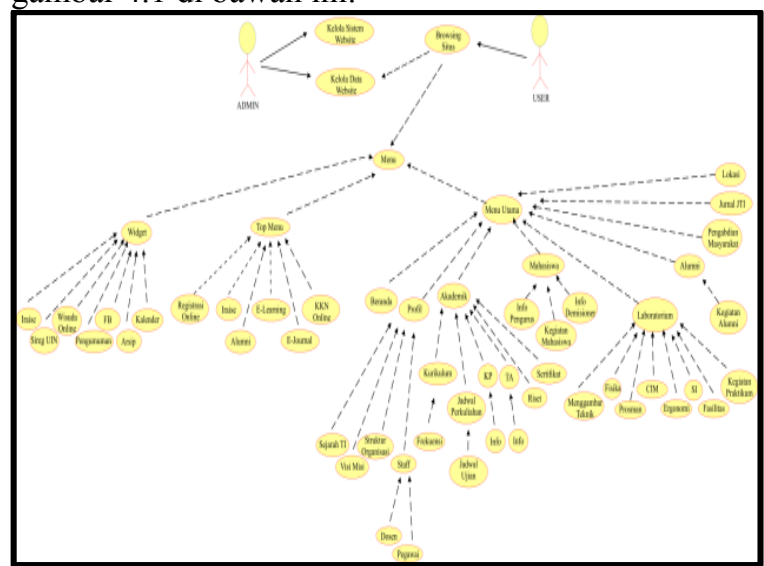

Gambar 3. Usecase Diagram

Pada Gambar 3 Usecase Diagram, terdapat menu-menu dan fitur-fitur yang dirancang dan akan diimplementasikan kedalam website.

\subsection{Activity Diagram}

Activity diagram adalah suatu diagram yang memodelkan alur kerja (workflow) sebuah proses dan urutan aktivitas dalam suatu proses. Adapun activity diagram pada penelitian ini adalah sebagai berikut :

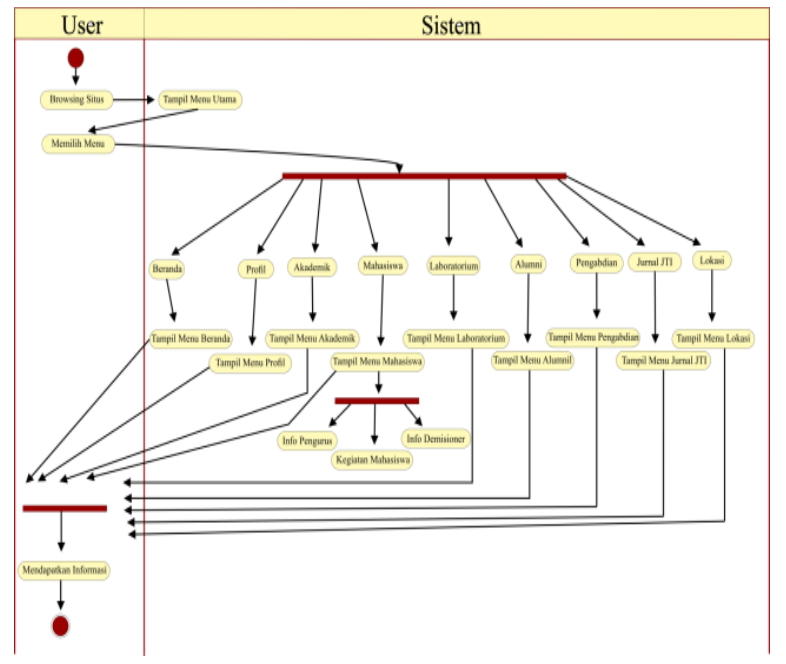

Gambar 4. Activity Diagram Menu Utama Pada gambar 4 dijelaskan alur dari proses browsing data sampai mendapatkan informasi yang ada pada menu utama.

\subsection{Sequence Diagram}

Sequence diagram adalah suatu diagram interaksi yang menekankan pada pengaturan waktu dari pesan-pesan. Adapun sequence diagram pada penelitian kali ini dapat dilihat pada gambar 4.6 dibawah ini :

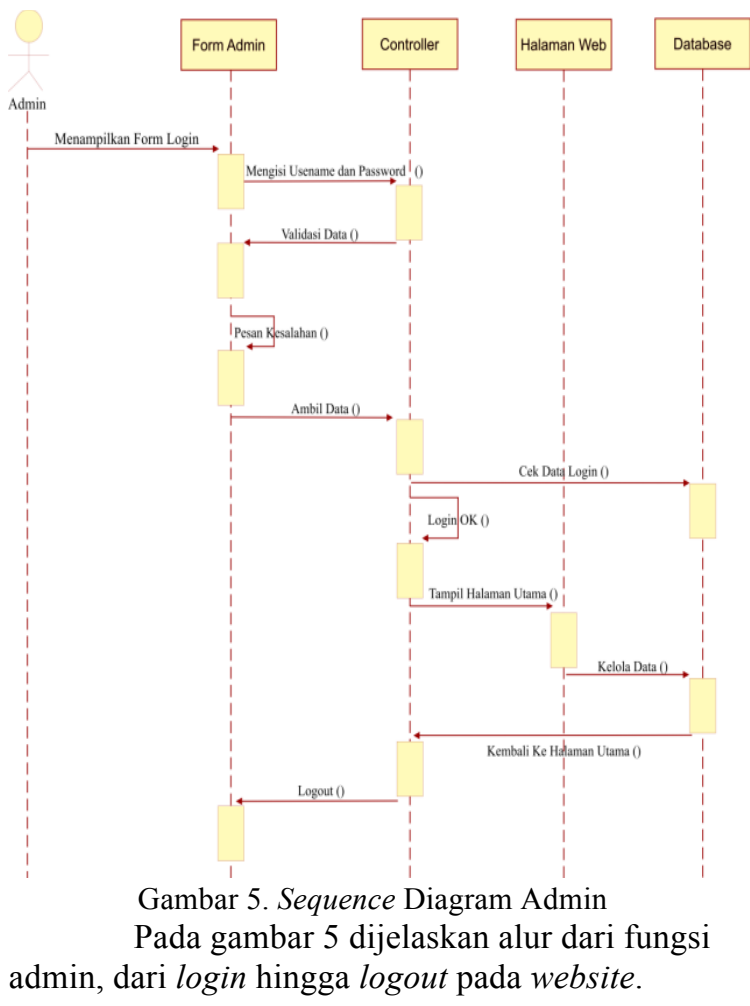

\section{Desain Antarmuka}

Desain antarmuka merupakan tampilan yang ada pada website berupa fitur-fitur seperti top menu, menu utama dan widget yang berguna untuk memudahkan pengguna dalam mencari informasi di dalam website. Adapun desain antarmuka pada website Teknik Industri Universitas Islam Sultan Syarif Kasim Riau adalah sebagai berikut : 


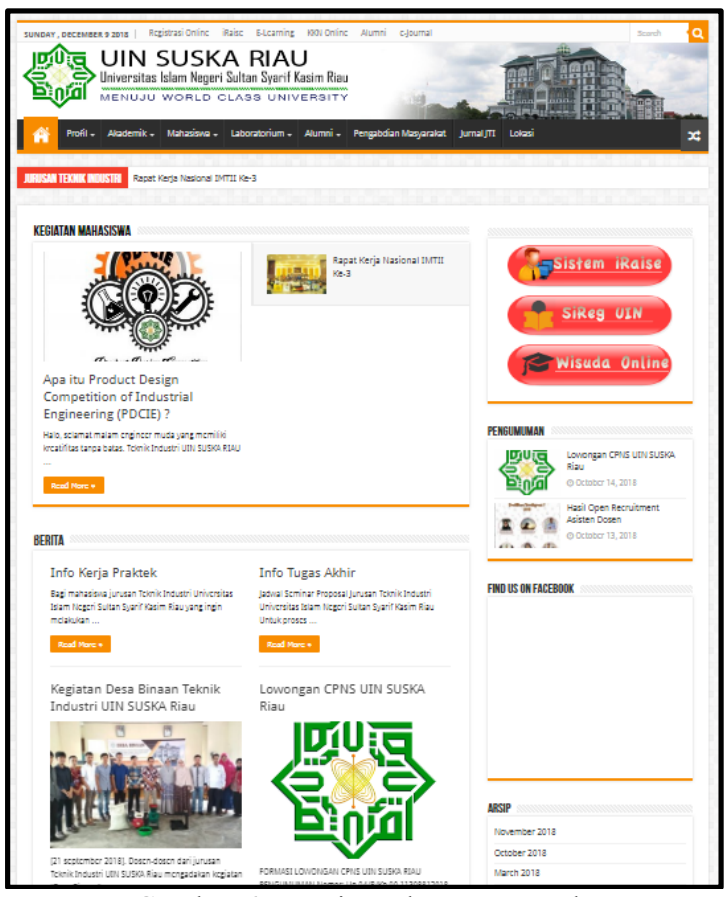

Gambar 6. Desain Halaman Beranda

\section{Halaman Admin}

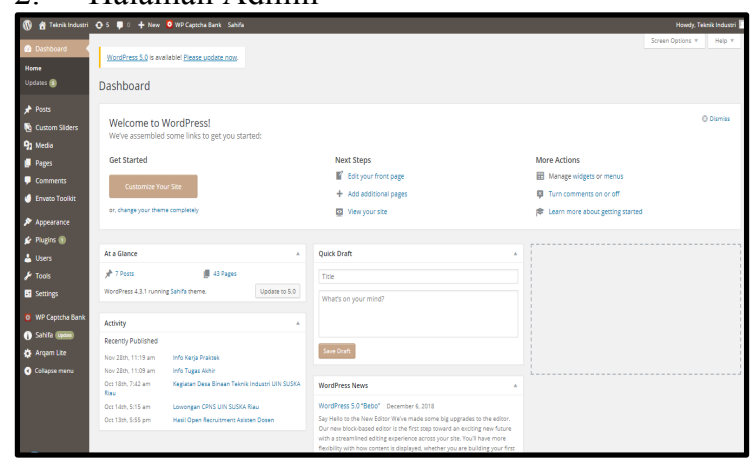

Gambar 7. Desain Halaman Admin

\section{Penulisan Program}

Pada penelitian kali ini, website dirancang menggunakan domain dari Universitas Islam Negeri Sultan Syarif Kasim Riau sehingga tidak lagi melakukan pemrograman data dikarenakan sudah ada template yang disediakan dari pihak universitas. Dalam mendesain website Teknik Industri UIN SUSKA Riau, digunakan sebuah sistem benama Wordpress. Wordpress berguna untuk login admin, memposting berita, menambahkan menu-menu yang diinginkan dan kebutuhan lain agar website memiliki tingkat usabilitas yang tinggi.

\section{Pengujian Usabilitas Desain Usulan}

Pengujian ini dilakukan untuk mengetahui tingkat usabilitas dari website Teknik Industri UIN
SUSKA Riau yang telah dirancang. Pengujian ini menggunakan kuesioner WEBUSE, kemudian kuesioner ini disebarkan kepada 35 orang responden dah hasil rekapan kuesioner dapat dilihat di lampiran.

Hasil dari perhitungan setiap atribut dapat dilihat pada grafik berikut ini :

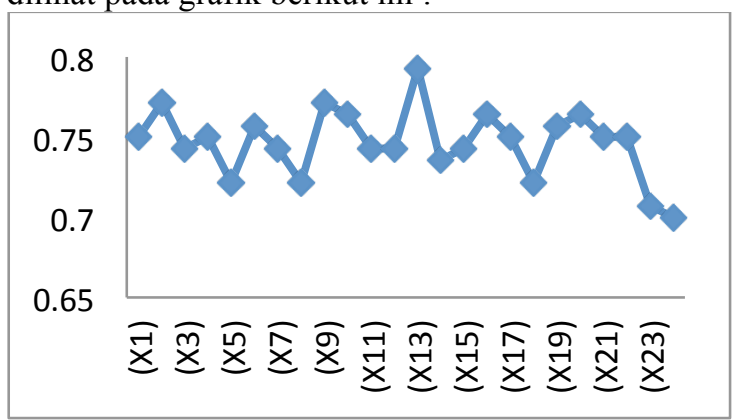

Gambar 8. Grafik Usabilitas Website per Atribut

Sedangkan hasil perhitungan usabilitas per dimensi dapat dilihat pada tabel 2 berikut ini :

Tabel 2 Rekap Data per Dimensi

\begin{tabular}{|c|l|l|c|}
\hline No & Kategori & Point & $\begin{array}{c}\text { Level } \\
\text { Usabilitas }\end{array}$ \\
\hline 1 & $\begin{array}{l}\text { Content, Organization, } \\
\text { and Readability }\end{array}$ & 0.7488 & Good \\
\hline 2 & Navigation and Links & 0.7476 & Good \\
\hline 3 & Desain User Interface & 0.7512 & Good \\
\hline 4 & $\begin{array}{l}\text { Performance and } \\
\text { Effectiveness }\end{array}$ & 0.7381 & Good \\
\hline
\end{tabular}

(Sumber : Pengolahan Data, 2018)

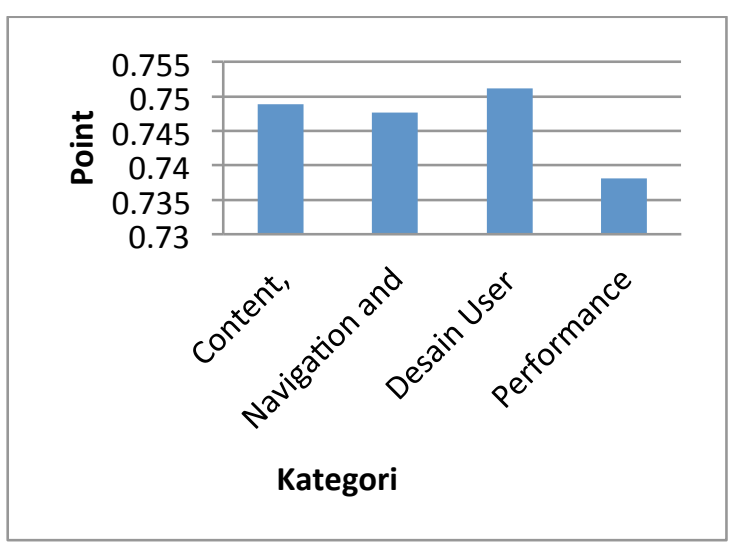

Gambar 9. Grafik Usabilitas Website per Dimensi

8. Operation and Maintenance

Pada tahap terakhir akan dilakukan pemeliharaan sistem dengan cara mengusulkan SOP pemeliharaan sehingga website dapat terjaga dan dapat update dalam berbagi informasi. Agar website selalu memberikan informasi yang update 
maka diusulkan kepada pihak jurusan untuk menjalin kerja sama dengan Himpunan Mahasiswa Jurusan (HMJ) Teknik Industri Universitas Islam Negeri Sultan Syarif Kasim Riau.

Pada usulan pemeliharaan, terdapat 2 tim dalam pemeliharaan website yaitu Admin dan Tim Jurnalis. Adapun tugas dari tim tersebut dan jumlah anggota yang dibutuhkan adalah sebagai berikut :

1. Admin

Admin bertugas dalam menambahkan informasi dan menambahkan fitur-fitur yang terbaru agar tampilan website lebih baik kedepannya. Adapaun anggota yang dibutuhkan sebanyak 2 orang dengan kriteria memahami penggunaan wodpress.

2. Tim Jurnalis

Tim Jurnalis ini bertugas dalam membuat dan mencari sebuah berita, artikel, atau informasi yang akan dimasukkan kedalam website tersebut. Adapun anggota yang dibutuhkan sebanyak 5 orang dengan kriteria pernah menulis artikel atau mengisi berita di mading dan dapat bekerja dalam kelompok.

Dalam pemeliharaan website ada hal-hal yang harus dilakukan agar website terjaga dan terupdate, dengan ini diusulkan suatu SOP untuk pemeliharaan website tersebut. Adapun Standard Operating Procedure (SOP) yang diajukan kepada pengurus HMJ dalam pemeliharaan website adalah sebagai berikut :

Tabel 3 Standard Operating Procedure (SOP) Pemeliharaan website

\begin{tabular}{|l|l|}
\hline No & \multicolumn{1}{|c|}{ Kegiatan } \\
\hline 1 & Memberikan informasi yang terupdate \\
\hline 2 & Melakukan desain ulang tampilan website secara berkala \\
\hline 3 & $\begin{array}{l}\text { Memonitoring secara berkala status pembaharuan } \\
\text { content (updating) }\end{array}$ \\
\hline 4 & $\begin{array}{l}\text { Melakukan backup seluruh data dan informasi pada } \\
\text { website secara berkala kedalam media backup seperti } \\
\text { CD, Flashdisk maupun Harddisk }\end{array}$ \\
\hline 5 & $\begin{array}{l}\text { Memonitoring aktivitas pengunjung dalam melihat } \\
\text { content yang telah di publish }\end{array}$ \\
\hline 6 & $\begin{array}{l}\text { Melaporkan situasi, kondisi, permasalahan dan alternatif } \\
\text { pemecahan masalah website kepada penanggung jawab } \\
\text { informasi }\end{array}$ \\
\hline 7 & $\begin{array}{l}\text { Mengambil langkah-langkah pemecahan masalah yang } \\
\text { ditemui dalam pengelolaan informasi atau website. }\end{array}$ \\
\hline 8 & $\begin{array}{l}\text { Melakukan atau menyelesaikan pemecahan masalah } \\
\text { secara mandiri ataupun melibatkan pihak ketiga }\end{array}$ \\
\hline
\end{tabular}

(Sumber : Pengolahan Data, 2018)

\section{Kesimpulan}

\section{Kesimpulan}

Berdasarkan tujuan yang telah dijelaskan pada penelitian ini, maka kesimpulan pada penelitian ini yaitu:

1. Website jurusan Teknik Industri Universitas Islam Negeri Sultan Syarif Kasim Riau telah dirancang dengan beralamatkan http://ie.uinsuska.ac.id dan telah mempublish berita-berita kegiatan di jurusan Teknik Industri Universitas Islam Negeri Sultan Syarif Kasim Riau.

2. Website jurusan Teknik Industri Universitas Islam Negeri Sultan Syarif Kasim Riau memiliki beberapa menu-menu diantaranya adalah menu profil, akademik, mahasiswa, laboratorium, alumni, pengabdian masyarakat, jurnal JTI dan lokasi.

3. Tingkat usabilitas pada website Teknik Industri berada pada level good, yang mana rincian nilai usabilitas website Teknik Industri adalah Content, Organization, and Readability bernilai 0.7488 , Navigation and Link bernilai 0.7476 , Desain User Interface bernilai 0.7512 dan Performance and Effectiveness bernilai 0.7381 .

4. Standar Operating Procedure (SOP) telah diajukan kepada pihak HMJ yang mewadahi segala aktivitas dari website jurusan Teknik Industri Universitas Islam Negeri Sultan Syarif Kasim Riau.

\section{Saran}

Saran yang dapat diberikan pada penelitian selanjutnya adalah sebagai Berikut :

Hasil usabilitas desain baru pada penelitian ini yang masih berada pada range nilai $0,6-0,8$. Sehingga dimungkinkan untuk dilakukan penelitian lebih lanjut agar level usabilitas berada pada range nilai $0,8-1$. Untuk penelitian selanjutnya dapat menggunakan selain model waterfall, sehingga dapat menghasilkan website yang memudahkan pengguna baik dari segi tingkat usabilitas maupun sistem yang lebih baik lagi.

\section{Daftar Pustaka}

Bassil, Y. A Simulation Model for the Waterfall Software Development Life Cycle. International Journal of 
Engineering \& Technology (IJET) Vol. 2, No. 5, ISSN: 2049-3444, 2012.

[2] Chiew, T.K., dan Salim, S.S. WEBUSE: Website Usability Evaluation Tool. Malaysian Journal of Computer Science Vol. 16, No. 1, 47-57, 2003.

[3] Hendini, A. Pemodelan UML Sistem Informasi Monitoring Penjualan dan Stok Barang. Jurnal Khatulistiwa Informatika Vol. IV, No. 2, 2016.

[4] Ichsani, Y. Evaluasi Performa Usability Situs-situs Web Perguruan Tinggi Negeri di Indonesia yang Terakreditasi " $A$ " Tahun 2013 Serta Perbandingan Kondisi Situs Web Tahun 2014 dan 2017. Jurnal Teknik Informatika Vol. 10, No. 2, 2017.

[5] Lasminiasih., Sandhi, P., Akbar, A., Andriansyah, M., dan Utomo, R.B. Perancangan Sistem Informasi Kredit Mikro Mahasiswa Berbasis Web. Jurnal Sistem Informasi (JSI) Vol. 8, No. 1, ISSN: 2085-1588, 2016.

[6] Nielsen, J. Usability 101: Introduction to Usability. ISSN: 1548-5552, 2003.

[7] Masadeh, M.A. Focus Group: Review and Practices. International Journal of Applied Science and Technology Vol. 2, No. 10, 2012.

[8] Rachmi, A., Susanto, T.D., dan Herdiyanti, A. Pembuatan Standard Operating Procedure (SOP) Service Desk Berdasarkan Kerangka Kerja Itil V3 dengan Menggunakan Metode Analisis Gap Layanan. Jurnal Teknik POMITS Vol. 3, No. 2, ISSN: 2337-3539, 2014.

[9] Rubin, J., dan Chisnell, D. 2008. Handbook of Usability Testing, How to Plan, Design, and Conduct Effective Test. Indianapolis: Wiley Publishing.

[10] Wirandoko, G. Perancangan Ulang User Interface E-Pustaka Teknik Industri UNS Berdasarkan Aspek Usabilitas Menggunakan Metode Focus Group Discussion, Tugas Akhir, Jurusan Teknik Industri, Universitas Sebelas Maret, Surakarta, 2009.

[11] Yumarlin, M.Z. Evaluasi Penggunaan Website Universitas Janabadra dengan Menggunakan Metode Usability Testing. Jurnal Informasi Interaktif Vol. 1, No. 1, ISSN: $\quad 2527-5240, \quad 2016$. 
Vol. 4, No. 2, 2018

Jurnal Hasil Penelitian dan Karya Ilmiah dalam Bidang Teknik Industri 